\title{
Cataract complications study: an analysis of adverse effects among 14,520 eyes in relation to surgical experience
}

\author{
Alexander Aaronson ${ }^{1,2}$, Antti Viljanen ${ }^{3,4}$, Piotr Kanclerz ${ }^{5}$, Andrzej Grzybowski ${ }^{6,7}$, Raimo Tuuminen ${ }^{1,8}$ \\ ${ }^{1}$ Helsinki Retina Research Group, University of Helsinki, Helsinki, Finland; ${ }^{2}$ Department of Ophthalmology, Helsinki University Hospital, Helsinki, \\ Finland; ${ }^{3}$ Medical Faculty, University of Turku, Turku, Finland; ${ }^{4}$ Medilaser and Coronaria, Cor Group, Finland; ${ }^{5}$ Hygeia Clinic, Gdańsk, Poland; \\ ${ }^{6}$ Department of Ophthalmology, University of Warmia and Mazury, Olsztyn, Poland; ${ }^{7}$ Institute for Research in Ophthalmology, Foundation for \\ Ophthalmology Development, Poznan, Poland; ${ }^{8}$ Kymenlaakso Central Hospital, Unit of Ophthalmology, Kotka, Finland \\ Contributions: (I) Conception and design: All authors; (II) Administrative support: R Tuuminen; (III) Provision of study materials or patients: A \\ Aaronson, R Tuuminen; (IV) Collection and assembly of data: A Aaronson, R Tuuminen; (V) Data analysis and interpretation: All authors; (VI) \\ Manuscript writing: All authors; (VII) Final approval of manuscript: All authors. \\ Correspondence to: Raimo Tuuminen, MD, PhD, FEBO. Associate Professor, Chief Physician, Kymenlaakso Central Hospital, Unit of Ophthalmology, \\ Kotkantie 41, FI-48210 Kotka, Finland. Email: raimo.tuuminen@helsinki.fi.
}

\begin{abstract}
Background: To evaluate the learning-curve in performing cataract surgery with respect to developments in technology and different teaching strategies by comparing the incidence of capsular bag-related complications to operator experience.

Methods: A review of the registry of 14,520 cataract surgeries carried out at the Ophthalmology Unit of Kymenlaakso Central Hospital, Kotka, Finland, from August 8, 2009 to July 31, 2017.

Results: We identified 144 cases with posterior capsule rupture and/or loss of capsular bag support (incidence $0.99 \%$ of all surgeries). The mean age of patients was $76.9 \pm 9.1$ years and gender distribution ratio 29:71 male:female. Pseudoexfoliation syndrome (PXF; incidence 21\%) and small pupil (incidence 14\%) were over-represented in complication eyes, especially at the beginning of the study. Capsular bag-related complication rates were reported in $0.36 \%$ of surgeries for senior and $7.03 \%$ for resident surgeons at the beginning of the study, compared to $0.32 \%$ and $1.32 \%$, respectively, at the end of the study. Best-corrected visual acuity at the final post-operative visit was $0.61 \pm 0.16$ decimals at the beginning of the study, and $0.81 \pm 0.19$ decimals at the end of the study. The mean number of post-operative visits was $4.3 \pm 2.7$ and did not show trend over the study period.
\end{abstract}

Conclusions: Real-world evidence suggests PXF and small pupil as significant risk factors in cataract surgery. A gradual decline in the rate complications was noted with increasing surgical experience, also among residents over the follow-up period.

Keywords: Cataract surgery; complication; learning-curve; posterior capsule rupture; zonular dialysis

Submitted Jan 17, 2020. Accepted for publication Mar 26, 2020.

doi: 10.21037/atm-20-845

View this article at: http://dx.doi.org/10.21037/atm-20-845

\section{Introduction}

Technological advancement has made cataract surgeries faster and safer. Regardless the general decline observed in rates of adverse events several patient and ophthalmic characteristics have been associated with increased risk of perioperative complications. These characteristics comprise e.g., pseudoexfoliation (PXF) and zonular weakness, use of a1-blockers, dense cataracts and poor mydriasis (1). Moreover, the level of surgeons' experience and annual operation volume were recognized as factors correlating with the frequency of cataract surgery adverse events. Among patients over 90 years of age, ocular comorbidity and worse preoperative visual acuity also significantly 
increased the risk of complications (2).

A variety of methods have been applied to assess the resident-performed cataract operations learning curve including. Evaluation of the frequency of complications [particularly posterior capsule rupture (PCR)], the frequency of attending surgeon takeovers, or the gradual decline in the operation time $(1,3)$. Complication rates were found to decline significantly after the first 200 operations (4-6). A steadier decrease in the complication rate was noted at 3,000 phacoemulsifications (7). Remarkably, a peak in the complication rates was observed as a consequence of residents gaining experience followed by diminished supervisor intervention (8).

Poorly dilated pupils were associated with increased complication rates both for residents and senior surgeons (9), whereas iris complications were likely to take more time from resident surgeons (10). Longer cataract surgery operation time predicted lower visual outcomes (11) or poorer patient satisfaction (12). Furthermore, PXF and the use of $\alpha 1$-blockers were associated with reduced post-operative visual acuity (13). To reduce the rate of complications, such as PCR and vitreous loss, the installation of surgical curriculum in the residency program was suggested $(14,15)$. Posterior capsule rupture, in turn, was associated with 42 -fold risk for retinal detachement and 8 -fold risk for endophthalmitis within 3 months after cataract surgery (16). Implementation of wet-labs and surgical simulators in cataract surgery training were found comparably effective in terms of improving residents' surgical abilities, although residents with wet-lab training required less operation time (17). In a large study the use of surgery simulator was found to reduce the PCR rate by $38 \%$ (18). The use of simulators has been shown to improve surgical skills among novice and even intermediate level surgeons $(19,20)$. In addition, simulators can be used to assess competency in ocular surgery (21). A method for a systematic step-by-step assessment of resident performed cataract operations was developed to better recognize the sites of improvement (22). An attempt has been made to pre-evaluate a surgeon's risk for PCR with respect to surgeon experience level (23).

Here, we examined the frequency of posterior capsule rupture and/or loss of capsular bag support between years 2009-2017 with respect to surgical experience. Further, we analyzed the outcomes of eyes with complications and discuss advances in surgical operation training during the study period.

\section{Methods}

This study was carried out as a retrospective cohort study at the Unit of Ophthalmology, Kymenlaakso Central Hospital, Kotka, Finland. The study was approved by the Research Director and Chief Medical Officer of the Kymenlaakso Central Hospital and the tenets of the Declaration of Helsinki were followed. Confidentiality of the patient records was maintained when the clinical data were entered into a computer-based standardized data base for analysis.

\section{Patients}

We reviewed the registry of operations for phacoemulsification cataract surgeries and posterior capsule ruptures and/or loss of capsular bag support between $1 / 8 / 2009$ and $31 / 7 / 2017$. Indications for phacoemulsification cataract surgery were based on the National Current Care Guidelines for Senile Cataract Surgery. The patient age distribution over the study period is represented in Figure S1. The Guidelines remained constant regarding patient eligibility for surgery "A patient is eligible for referral when best-corrected visual acuity (BCVA) in the better eye is $\leq 0.5$ and in the weaker eye $\leq 0.3$ measured in E-snellen lines" [Duodecim 2010;126(21):2541-2, updated in year 2013].

\section{Surgery}

The pre- and intraoperative methods employed to decrease the rate complications are summarized in Table 1. Structured referral for cataract surgery was demanded for all patients from year 2014 onwards (Figure 1). Simultaneously, cataract surgery risk stratification was implemented for coordination of operations with respect to the required level of surgeon competency (Table S1).

The patients were examined by the operating ophthalmologist preoperatively on the day of surgery. Cataract surgeries were performed by three seniors, three specialists, and 19 residents in ophthalmology. The level of surgical skill between specialists and seniors was defined according the surgical education responsibilities. Seniors are supervising doctors in ophthalmic surgery for residents, while specialists have finished their residency and work as independent full-time employees. All three specialists had performed their surgical training already during residency. For the residents, only the first 100 operations were counted to the registry to maintain the follow-up throughout the 
Table 1 Methods employed to decrease the rate of operative complications in cataract surgery in Kymenlaakso Central Hospital, Kotka, Finland, during the years 2009-2017

\begin{tabular}{|c|c|c|}
\hline Action & Date & Effect on cataract surgery \\
\hline Wet-labs & 2011 & Porcine eyes replaced rubber eyes - allows improvement in practical skills \\
\hline Surgical curriculum & 2014 & Oculoplastic training before cataract surgery - surgical experience \\
\hline Structured referral & 2014 & Systematic risk stratification, patient allocation according to surgeon's experience level ${ }^{\star}$ \\
\hline \multicolumn{3}{|l|}{ Intraoperative phase } \\
\hline OVDs & 2009 & Viscous dispersive DiscoVisc ${ }^{\circledR}$ OVD - improved space maintenance, ease of removal \\
\hline One-Piece IOLs & 2009 & $\begin{array}{l}\text { One-Piece IOLs as principal choice both for clear and blue-light filtering IOLs. Ease of } \\
\text { manipulation in the capsular bag }\end{array}$ \\
\hline Senior in adjacent OR & 2013 & Consultation made easy \\
\hline Silicone tip for $\mathrm{l} / \mathrm{A}$ & 2013 & Enhanced safety in posterior capsule polishing \\
\hline Pupil expansion device & 2014 & $\begin{array}{l}\text { Malyugin ring }{ }^{\circledR} 6.25 \mathrm{~mm} \text { replacing iris hooks - reduced manipulation of the iris, reduced } \\
\text { operation time }\end{array}$ \\
\hline Surgical microscopes & 2015 and 2016 & $\begin{array}{l}\text { Zeiss OPMI Lumera } 700 \text { and Leica M844 F40 replacing Zeiss S4 and S5 microscopes - video } \\
\text { recording for feedback and learning difficult steps }\end{array}$ \\
\hline Preloaded IOLs & 2015 and 2016 & $\begin{array}{l}\text { AU00T0, AcrySof }{ }^{\circledR} \mathrm{IQ}, \mathrm{SN60WF} \text { in UltraSertTM delivery system, Alcon and PCB00, Tecnis }{ }^{\circledR} \mathrm{IOL} \\
\text { in iTec }{ }^{\circledR} \text { delivery system, Johnson \& Johnson Vision - reduces need for IOL manipulation }\end{array}$ \\
\hline
\end{tabular}

I/A, irrigation \& aspiration; IOL, intraocular lens; OR, operation room; OVD, ophthalmic viscosurgical device. *, please see Figure 1 and Table S1.

study period comparable as some of the residents performed markedly higher numbers of surgeries.

A $2.75 \mathrm{~mm}$ clear cornea incision was used throughout the study period. The predominant phacoemulsification technique over the study period was divide and conquer (hrrg.fi/en/videos/cataract/).

\section{Data analysis}

Data are given as mean $\pm \mathrm{SD}$, except for the absolute numbers and proportions for the nominal scale. IBM SPSS Statistics 25 (SPSS Inc., Somers, NY, USA) was used for data analysis. Categorical data were analyzed with the two-factor chi-square test. BCVA was analyzed with nonparametric Mann-Whitney $U$ test and normallydistributed continuous variables with the t-test. A mixedeffects logistic regression model, incorporating repeated measurements, was fitted during the statistical analysis.
$\mathrm{P} \leq 0.05$ was considered statistically significant.

\section{Results}

\section{Baseline variables}

The number of operated eyes were 10,724 for seniors (73.9\% of all operations), 2,473 for specialists (17.0\%), and 1,323 for residents (9.1\%) (Table 2). Of the total 144 PCR and/or loss of capsular bag support (total incidence from 14,520 surgeries; $0.99 \%$ ), 75 were recorded at the phacoemulsification phase $(52.1 \%), 34$ at the irrigation/ aspiration (I/A) phase (23.6\%), 10 at the IOL implantation phase $(6.9 \%)$, and 25 in non-specified/other phase of the surgery (17.4\%) (Table 3, Table S2).

Baseline variables of eyes with complications regarding the age and gender distribution, BCVA, incidence of small pupils and PXF are presented in Table 4. Baseline characteristics indicate poorer BCVA, and 
Carea ${ }^{\circledR}$

Kymenlaakson sairaanhoito- ja
sosiaalipalvelujen kuntayhtymä
Department of Ophthalmology Kymenlaakso Central Hospital Kotkantie 41, 48210 Kotka

\section{Referral for Cataract Operation}

Patient name:

Right eye $\square$ Left eye $\square$ Both eyes OPERATION TIMEFRAME

Medical indication for urgent cataract operation (lens induced angle-closure)

Social indication for urgent cataract operation (e.g. occupation)

BACKGROUND INFORMATION

Tremor or other condition that may complicate the operation

Alpha-1 blockers due to benign prostatic hyperplasia

Diabetes

lodine or rubber allergy

Unable to lay on the operation table for a half an hour

PREVIOUS OCULAR DISEASE

Prior ocular surgeries (PRK/LASIK, vitrectomy, filtration surgery)

Inflammatory ocular diseases (iritis, chronic blepharitis)

Other vision impairing ocular condition (amblyopia, AMD)

\section{CURRENT CLINICAL STATUS}

\begin{tabular}{|c|c|c|c|c|c|}
\hline \multicolumn{3}{|l|}{ BCVA and correction } & \multicolumn{3}{|l|}{ BCVA and correction } \\
\hline IOP & & & $\mathrm{IOP}$ & & \\
\hline & NO & YES & & NO & YES \\
\hline Corneal opacities & $\square$ & $\square$ & Corneal opacities & $\square$ & $\square$ \\
\hline Shallow anterior chamber & $\square$ & $\square$ & Shallow anterior chamber & $\square$ & $\square$ \\
\hline Small pupil in mydriasis & $\square$ & $\square$ & Small pupil in mydriasis & $\square$ & $\square$ \\
\hline Mature cataract & $\square$ & $\square$ & Mature cataract & $\square$ & $\square$ \\
\hline Pseudoexfoliation & $\square$ & $\square$ & Pseudoexfoliation & $\square$ & $\square$ \\
\hline Phacodonesis & $\square$ & $\square$ & Phacodonesis & $\square$ & $\square$ \\
\hline Pseudophakia & $\square$ & $\square$ & Pseudophakia & $\square$ & $\square$ \\
\hline
\end{tabular}

Other relevant information (e.g. difficulty to maintain fixation)

\begin{tabular}{|l|l|}
\hline & \\
Referring organization and date & Referring doctor and signature \\
\hline
\end{tabular}
RECEIVING UNIT EVALUATION Urgency I $\square$ II $\square$ Surgeon seniority $A \square B \square C \square$

Figure 1 Referral for cataract operation. AMD, age-related macular degeneration; BCVA, best-corrected visual acuity; IOP, intraocular pressure. 
Table 2 Incidence (\%) of posterior capsule rupture and/or loss of capsular bag support according to surgical experience

\begin{tabular}{lccc}
\hline Time period & $\begin{array}{c}\text { Senior } \\
(\mathrm{n}=3)\end{array}$ & $\begin{array}{c}\text { Specialist } \\
(\mathrm{n}=3)\end{array}$ & $\begin{array}{c}\text { Resident } \\
(\mathrm{n}=19)\end{array}$ \\
\hline $8 / 2009-7 / 2010$ & 0.36 & & 7.03 \\
$8 / 2010-7 / 2011$ & 0.46 & & 5.45 \\
$8 / 2011-7 / 2012$ & 0.42 & & 6.20 \\
$8 / 2012-7 / 2013$ & 0.32 & 4.22 & 4.27 \\
$8 / 2013-7 / 2014$ & 0.46 & 2.27 & 3.81 \\
$8 / 2014-7 / 2015$ & 0.31 & 1.99 & 3.82 \\
$8 / 2015-7 / 2016$ & 0.34 & 1.28 & 2.17 \\
$8 / 2016-7 / 2017$ & 0.32 & 0.67 & 1.32 \\
Overall & 0.39 & 1.86 & 4.23 \\
& $(\mathrm{n}=10,724)$ & $(\mathrm{n}=2,473)$ & $(\mathrm{n}=1,323)$ \\
\hline
\end{tabular}

Data are given as incidence (\%). Surgeon seniority defined by responsibility of surgical training of the Residents.

Table 3 Surgical phase when posterior capsule rupture and/or loss of capsular bag support was noticed

\begin{tabular}{lc}
\hline Surgical phase & $\mathrm{n}$ \\
\hline Total & 144 of 14,520 surgeries $(0.99 \%)$ \\
Phaco & 75 \\
I/A & 34 \\
IOL implantation & 10 \\
not specified/other & 25 \\
\hline
\end{tabular}

Data are given as absolute number $(\mathrm{N})$ and proportion (\%). I/A, irrigation aspiration; IOL, intraocular lens. overrepresentation of small pupils and PXF eyes subjected to complication towards the start of the study period (Table 4).

\section{Incidence and outcomes of PRC and/or loss of capsular bag support over the study period}

Over the study period the incidence of PCR and/or loss of capsular bag support remained constant among senior surgeons (from $0.36 \%$ to $0.32 \%$; range, $0.31-0.46 \%$, Table 2 ). Decline in the complication rates over the study period was observed among specialists (from $4.22 \%$ to $0.67 \%$; Table 2), and likewise among residents (from $7.03 \%$ to $1.32 \%$, Table 2). Overall, the frequency of cataract surgery complications has been decreasing since the year $2009(\mathrm{P}<0.001)$. Regarding surgeon's professional experience, a specialist was $46.6 \%$ (95\% CI: $15.3-66.4 \%, \mathrm{P}=0.008$ ) and a senior clinician was $92.4 \%$ (95\% CI: $88.1-95.1 \%, \mathrm{P}<0.001)$ less likely to encounter complications as compared to a resident. Interestingly, over the study period a senior clinician was $85.7 \%$ (95\% CI: $75.6-91.7 \%, \mathrm{P}<0.001)$ less likely to encounter complications when compared to a specialist.

The number of post-operative visits was $3.5 \pm 1.7$ at the beginning of the study period and $3.0 \pm 1.7$ at the end of the study period (Table 5). BCVA at the final visit was $0.61 \pm 0.16$ decimals at the beginning of the study period and $0.81 \pm 0.19$ decimals at the end of the study period (Table 5).

The number of post-operative visits and BCVA at the final post-operative visit was comparable between surgeries performed by the residents and non-residents (Table S3), and between complications according to the surgical phase (Table S4). Small pupils and PXF were overrepresented

Table 4 Baseline characteristics of eyes with posterior capsule rupture and/or loss of capsular bag support

\begin{tabular}{lccccc}
\hline Time period & Age $(\mathrm{y})$ & M:F (\%) & BCVA (decimals) & Small pupil (\%) & PXF (\%) \\
\hline 8/2009-7/2010 & $68.5 \pm 15.7[47-82]$ & $25: 75$ & $0.27 \pm 0.17(\mathrm{HM}-0.5)$ & 16 & 24 \\
$8 / 2010-7 / 2011$ & $76.7 \pm 6.8[64-86]$ & $33: 67$ & $0.25 \pm 0.08(0.1-0.3)$ & 30 \\
$8 / 2011-7 / 2012$ & $80.3 \pm 7.3[63-95]$ & $13: 87$ & $0.26 \pm 0.20(\mathrm{CF}-0.5)$ & 7 \\
$8 / 2012-7 / 2013$ & $78.1 \pm 7.7[64-90]$ & $29: 71$ & $0.27 \pm 0.13(0.05-0.5)$ & 36 \\
$8 / 2013-7 / 2014$ & $78.8 \pm 5.0[69-86]$ & $24: 76$ & $0.22 \pm 0.15(\mathrm{HM}-0.5)$ & 20 & 19 \\
$8 / 2014-7 / 2015$ & $75.7 \pm 8.7[57-89]$ & $45: 55$ & $0.29 \pm 0.15(0.05-0.5)$ & 4 \\
$8 / 2015-7 / 2016$ & $75.6 \pm 10.2[45-90]$ & $21: 79$ & $0.31 \pm 0.18(\mathrm{CF}-0.5)$ & 29 \\
$8 / 2016-7 / 2017$ & $78.2 \pm 11.9[48-97]$ & $50: 50$ & $0.47 \pm 0.29(0.3-0.8)$ & 0 & 0 \\
\hline
\end{tabular}

Data are given as mean \pm SD and range or proportion (\%). BCVA, best-corrected visual acuity in decimals; CF, counting fingers; F, female; $\mathrm{HM}$, hand motion; $\mathrm{M}$, male; PXF, pseudoexfoliation syndrome. 
Table 5 Outcomes of posterior capsule rupture and/or loss of capsular bag support

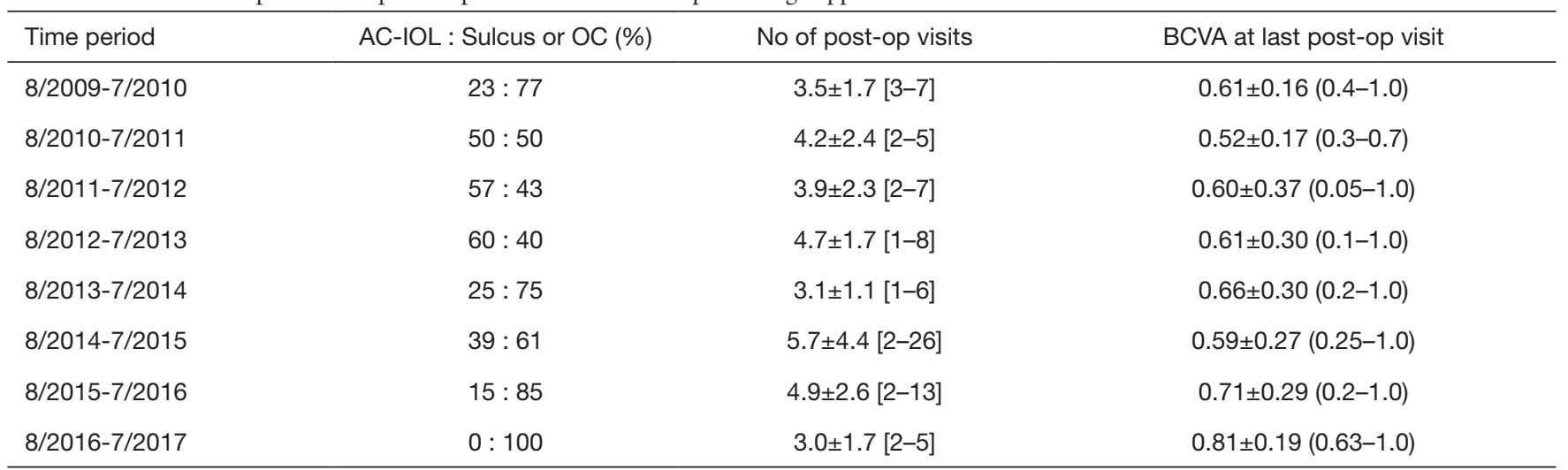

Data are given as proportions (\%) or mean \pm SD and range. AC, anterior chamber; BCVA, best-corrected visual acuity; IOL, intraocular lens; OC, optic capture.

in eyes with a need for AC-IOL (incidence of small pupils $24 \%$ vs. $9 \%, \mathrm{P}=0.013$, and of $\mathrm{PXF} 42 \%$ vs. $9 \%, \mathrm{P}<0.001$, among those with and without AC-IOL, Table S5). With respect to IOL positioning, having anterior chamber (AC)IOL the number of post-operative visits was higher $(5.2 \pm 3.5$ vs. 3.8 $\pm 2.1, \mathrm{P}=0.006$, Table S5) and BCVA at the final postoperative visit lower $(0.46 \pm 0.27$ vs. $0.71 \pm 0.23, \mathrm{P}<0.001$, Table S5) when compared to complications without the need for AC-IOL.

\section{Discussion}

The safety of patients must be guaranteed in public teaching hospitals particularly when surgeries are performed by non-skilled residents. Phacoemulsification cataract surgery has a relatively steep and long learning curve (24). For example, the study by Randleman et al. showed that the risk of PCR is $6.3 \%$ in the first 80 cases and $3.5 \%$ in the next 80 surgeries, which is much higher than the complication rates reported in large studies $(5,25)$. In another investigation, the overall PCR rate in residentperformed surgeries reached $17.3 \%$ in 183 cases (26). Various methods have been utilized to decrease the risk of complications in resident-performed surgeries including early introduction of cataract surgery training during the residency (15), one-step rather than stepwise introduction of various surgical maneuvers (26), employing an extensive surgical curriculum (14) along with surgical simulator (27) and wet-lab training. Moreover, the use of risk stratification system prior to cataract surgery is widely accepted and practiced with small variations around the world (1). For example, it has been suggested that the Buckinhamshire risk assessment better correlates with post-operative complications, while the Muhtaseb variation is more accurate in predicting intraoperative complications (28). A structured risk stratification not only allows routine assessment by referring ophthalmologists, but also helps in gathering information for systematic evaluation.

Within our study it is difficult to relate the risk reductions to any single improvement, either in the preoperative or perioperative phase. During the followup and assessment of the study, the national guidelines have remained the same for cataract surgery eligibility. The patients' average age at surgery has also remained constant. Thus, the indications for surgery are comparable throughout the study period. In this single site retrospective cohort study, we found a gradually declining rate of complications among residents and improved BCVA at the final visit towards the end of the study period, whereas no significant variation was observed in the number of postoperative visits. The use of AC-IOL was associated with a higher number of post-operative visits and the lower BCVA at final postoperative visit.

Small pupils and PXF were more frequent among non-resident surgeons when compared to the residents, which reflects the allocation of risk patients with the risk stratification system. The greater rate of female patients in resident-performed surgeries compared to non-residents could be associated with patient stratification; e.g., the medical treatment for benign prostatic hyperplasia involves predominantly men and such patients were directed to more experienced non-resident surgeons. This partially could have accounted for our low complication rates; within the final period of our study the incidence of PCR among 
Table 6 Studies analyzing the posterior capsule rupture rate (PCR) in resident-performed phacoemulsification cataract surgeries (published within the last 10 years and involving a minimum number of 100 surgeries per study)

\begin{tabular}{|c|c|c|c|}
\hline Study & $\begin{array}{l}\text { Patient risk } \\
\text { stratification }\end{array}$ & What did the study evaluate? & $\begin{array}{l}\text { PCR rate } \\
\text { (total number of cases) }\end{array}$ \\
\hline $\begin{array}{l}\text { Borboli-Gerogiannis } \\
\text { et al. } 2019\end{array}$ & $\begin{array}{l}\text { Yes (complicated } \\
\text { cases excluded) }\end{array}$ & $\begin{array}{l}\text { Before }(n=804) \text { vs. after }(n=1,282) \text { employing extended surgical } \\
\text { curriculum (including pre-OR, intra-OR and post-OR training) }\end{array}$ & $7.7 \%$ vs. $1.4 \% *$ \\
\hline Ellis et al. 2018 & Yes & $\begin{array}{l}\text { Early (first year of residency; } n=540 \text { ) vs. late (during final year; } \\
n=780 \text { ) introduction of cataract surgery during residency }\end{array}$ & $\begin{array}{l}1.9 \% \text { vs. } 6.5 \% \text { (with anterior } \\
\text { vitrectomy) }\end{array}$ \\
\hline Low et al. 2018 & Not used formally & $\begin{array}{l}3,142 \text { cases, } 18 \% \text { of resident-performed surgeries conducted } \\
\text { with staff surgeon }\end{array}$ & $0.8 \%$ \\
\hline Clarke et al. 2017 & No & 1,290 cases & $7.0 \%$ \\
\hline Tzamalis et al. 2015 & $\mathrm{~N} / \mathrm{A}$ & $\begin{array}{l}\text { Step-by-step }(n=185) \text { vs. one-step }(n=317) \text { introduction of } \\
\text { difference phacoemulsification steps }\end{array}$ & $\begin{array}{l}17.3 \% \text { vs. } 7.3 \% \text { (with zonular } \\
\text { dehiscence and vitreous loss) }\end{array}$ \\
\hline Hashemi et al. 2013 & $\begin{array}{l}\text { Yes (complicated } \\
\text { cases excluded) }\end{array}$ & 500 patients & $9.6 \%$ \\
\hline Pokroy et al. 2013 & $\mathrm{~N} / \mathrm{A}$ & Virtual simulator training $(n=50)$ vs. no such training $(n=50)$ & $7.0 \%$ vs. $8.0 \%$ \\
\hline Yulan et al. 2013 & $\mathrm{~N} / \mathrm{A}$ & First 30 cases vs. last 30 cases $(n=1,013)$ & $10.8 \%$ vs. $1.7 \%$ \\
\hline Woodfield et al. 2011 & Yes & 2nd $(n=228)$ vs. 3rd year $(n=463)$ of residency & $7.0 \%$ vs. $4.8 \%$ \\
\hline $\begin{array}{l}\text { Carricondo et al. } \\
2010\end{array}$ & $\begin{array}{l}\text { Yes (complicated } \\
\text { cases excluded) }\end{array}$ & First 40 cases vs. the cases $41-80$ vs. cases 81 and more & $9.7 \%$ vs. $7.4 \%$ vs. $5.8 \%$ \\
\hline
\end{tabular}

*, statistically significant.

resident-performed surgeries was only $1.32 \%$. This is one of the lowest values reported for phacoemulsification cataract surgery \{Table 6 [Sources: (29-32)]\}. Low et al. presented a PCR rate of $0.8 \%$; however, in their study $18 \%$ of resident-performed cases were performed with an attending surgeon (33). Moreover, there was no difference in overall complication rates between resident and staff surgeons in their study, although it is not clear how patient selection was conducted. Low PCR rates, under $2 \%$, were also reported by other authors $(15,34,35)$; however, in some studies such low rates were achieved only in the final phase of training and not presented as an overall complication rate through the whole training period (35).

In addition to higher intraoperative complication rates, which obviously are related with insufficient surgical skills, also other hazards associated with resident training have been reported. Resident-performed cataract surgery can predispose to persistent postoperative inflammation; in the study by Patel et al. 6.6\% of eyes suffered from such inflammation which was classified as idiopathic, due to a complicated cataract surgery or nonadherence to topical therapy (36). Moreover, it is estimated that residentperformed surgeries can take up to 27 minutes longer than those performed by attending surgeon; this could translate to an average additional cost of $\$ 105.40$ per surgery with the cost of running an operating room in mind (37).

This study has several limitations. First, we could not specify the efficacy of any particular method employed to decrease the rate of complications during surgery. Thus, we cannot recommend one specific practice to improve 
surgical outcomes in resident-training. Second, we did not analyze the complication rates and the advancement in resident training in particular timeframes; this data could reveal more detailed information regarding the learning-curves. Nevertheless, we believe that our study presents real-life statistics and highlights the fact that with proper methodology it is possible to significantly decrease intraoperative complication rates among residents as well as experienced surgeons.

\section{What was known}

- Intraoperative complication rates for resident-perform cataract surgery vary greatly, however, in several studies they are higher than for experiences surgeons;

* Patients with PXF syndrome or with a small pupil are at risk of developing intraoperative complications during cataract surgery.

\section{What this paper adds}

* Several methods can be applied to decrease the complication rates in cataract surgery including patient risk stratification, employing virtual reality simulators and wet-lab training, irrigation/aspiration with a silicone tip and video recording for feedback;

* Within this study, we were able to reduce the posterior capsult rupture rate from $7.03 \%$ to $1.32 \%$ in residentperformed surgeries, and from $4.22 \%$ to $0.67 \%$ in specialist-surgeons.

\section{Acknowledgments}

We thank Ms. Reetta Österberg and Ms. Enni Särkkä for their valuable work as research assistants.

Funding: The study was supported by grants from the Finnish Eye Foundation, Finnish Ophthalmological Society, the Nissi Foundation, Orion Research Foundation, the Paulo Foundation, the Waldemar von Frenckell Foundation, Glaukooma tukisäätiö LUX, and the HUS Specific Catchment Area (ERVA) Clinical Research Grants.

\section{Footnote}

Provenance and Peer Review: This article was commissioned by the Guest Editor (Dr. Andrzej Grzybowski) for the series "Recent developments in cataract surgery" published in Annals of Translational Medicine. The article was sent for external peer review organized by the Guest Editor and the editorial office.
Conflicts of Interest: All authors have completed the ICMJE uniform disclosure form (available at http:// dx.doi.org/10.21037/atm-20-845). The series "Recent developments in cataract surgery" was commissioned by the editorial office without any funding or sponsorship. The authors have no other conflicts of interest to declare.

Ethical Statement: The authors are accountable for all aspects of the work in ensuring that questions related to the accuracy or integrity of any part of the work are appropriately investigated and resolved. The study was approved by the Research Director and Chief Medical Officer of the Kymenlaakso Central Hospital and the tenets of the Declaration of Helsinki were followed.

Open Access Statement: This is an Open Access article distributed in accordance with the Creative Commons Attribution-NonCommercial-NoDerivs 4.0 International License (CC BY-NC-ND 4.0), which permits the noncommercial replication and distribution of the article with the strict proviso that no changes or edits are made and the original work is properly cited (including links to both the formal publication through the relevant DOI and the license). See: https://creativecommons.org/licenses/by-nc-nd/4.0/.

\section{References}

1. Kaplowitz K, Yazdanie M, Abazari A. A review of teaching methods and outcomes of resident phacoemulsification. Surv Ophthalmol 2018;63:257-67.

2. Theodoropoulou S, Grzeda MT, Donachie PHJ, et al. The Royal College of Ophthalmologists' National Ophthalmology Database Study of cataract surgery. Report 5: Clinical outcome and risk factors for posterior capsule rupture and visual acuity loss following cataract surgery in patients aged 90 years and old. Eye 2019;33:1161-70.

3. Corey RP, Olson RJ. Surgical outcomes of cataract extractions performed by residents using phacoemulsification. J Cataract Refract Surg 1998;24:66-72.

4. Irvine S, Francis IC, Kappagoda MB, et al. The second two hundred cases of endocapsular phacoemulsification: The learning curve levels off. Aust N Z J Ophthalmol 1994;22:281.

5. Randleman JB, Wolfe JD, Woodward M et al. The resident surgeon phacoemulsification learning curve. Arch Ophthalmol 2007;125:1215-9.

6. Taravella MJ, Davidson R, Erlanger M, et al. Characterizing the learning curve in phacoemulsification. J 
Cataract Refract Surg 2011;37:1069-75.

7. Martin KRG, Burton RL. The phacoemulsification learning curve: Per-operative complications in the first 3000 cases of an experienced surgeon. Eye 2000;14:190-5.

8. Mangan MS, Atalay E, Arici C, et al. Comparison of different types of complications in the phacoemulsification surgery learning curve according to number of operations performed. Turk J Ophthalmol 2016;46:7-10.

9. Hashemi H, Mohammadpour M, Jabbarvand M, et al. Incidence of and risk factors for vitreous loss in residentperformed phacoemulsification surgery. J Cataract Refract Surg 2013;39:1377-82.

10. Moustafa GA, Borkar DS, McKay KM, et al. Outcomes in resident-performed cataract surgeries with iris challenges: Results from the Perioperative Care for Intraocular Lens study. J Cataract Refract Surg 2018;44:1469-77.

11. Schmidt CM, Sundararajan M, Biggerstaff KS, et al. Indications and outcomes of resident-performed cataract surgery requiring return to the operating room. J Cataract Refract Surg 2016;42:385-91.

12. Ylinen P, Taipale C, Lindholm JM, et al. Postoperative management in cataract surgery: nepafenac and preservative-free diclofenac compared. Acta Ophthalmol 2018;96:853-9.

13. Clarke C, Ali SF, Murri M, et al. Outcomes and complication rates of primary resident-performed cataract surgeries at a large tertiary-care county hospital. J Cataract Refract Surg 2017;43:1563-70.

14. Rogers GM, Oetting TA, Lee AG, et al. Impact of a structured surgical curriculum on ophthalmic resident cataract surgery complication rates. J Cataract Refract Surg 2009;35:1956-60.

15. Ellis EM, Lee JE, Saunders L, et al. Complication rates of resident-performed cataract surgery: Impact of early introduction of cataract surgery training. J Cataract Refract Surg 2018;44:1109-15.

16. Day AC, Donachie PH, Sparrow JM, et al. The Royal College of Ophthalmologists' National Ophthalmology Database study of cataract surgery: report 1 , visual outcomes and complications. Eye (Lond) 2015;29:552-60.

17. Daly MK, Gonzalez E, Siracuse-Lee D, et al. Efficacy of surgical simulator training versus traditional wet-lab training on operating room performance of ophthalmology residents during the capsulorhexis in cataract surgery. J Cataract Refract Surg 2013;39:1734-41.

18. Ferris JD, Donachie PH, Johnston RL, et al. Royal College of Ophthalmologists' National Ophthalmology Database study of cataract surgery: Report 6 . the impact of EyeSi virtual reality training on complications rates of cataract surgery performed by first and second year trainees. Br J Ophthalmol 2020. [Epub ahead of print].

19. Jacobsen MF, Konge L, Bach-Holm D, et al. Correlation of virtual reality performance with real-life cataract surgery performance. J Cataract Refract Surg 2019;45:1246-51.

20. Thomsen ASS, Bach-Holm D, Kjærbo H, et al. Operating Room Performance Improves after Proficiency-Based Virtual Reality Cataract Surgery Training. Ophthalmology 2017;124:524-31.

21. Thomsen ASS, Kiilgaard JF, Kjærbo H, et al. Simulationbased certification for cataract surgery. Acta Ophthalmol 2015;93:416-21.

22. Golnik C, Beaver H, Gauba V, et al. Development of a new valid, reliable, and internationally applicable assessment tool of residents' competence in ophthalmic surgery. Trans Am Ophthalmol Soc 2013;111:24-33.

23. Sparrow JM, Taylor H, Qureshi K, et al. The cataract national data set electronic multicentre audit of 55567 operations: Case-mix adjusted surgeons outcomes for posterior capsule rupture. Eye (Lond) 2011;25:1010-5.

24. Parihar J, Sahoo P, Dash R, et al. An advanced cataract surgery by phacoemulsification: an initial experience. Med J Armed Forces India 1998;54:229-31.

25. Jaycock P, Johnston RL, Taylor H, et al. The Cataract National Dataset electronic multi-centre audit of 55567 operations: Updating benchmark standards of care in the United Kingdom and internationally. Eye 2009;23:38-49.

26. Tzamalis A, Lamprogiannis L, Chalvatzis N, et al. Training of Resident Ophthalmologists in Cataract Surgery: A Comparative Study of Two Approaches. J Ophthalmol 2015;2015:932043.

27. Staropoli PC, Gregori NZ, Junk AK, et al. Surgical Simulation Training Reduces Intraoperative Cataract Surgery Complications Among Residents. Simul Healthc 2018;13:11-5.

28. Han JV, Patel DV, Wallace HB, et al. Auckland Cataract Study III: Refining Preoperative Assessment With Cataract Risk Stratification to Reduce Intraoperative Complications. Am J Ophthalmol 2019;200:253-4.

29. Carricondo PC, Fortes ACFM, Mourão P de C, et al. Senior resident phacoemulsification learning cure. Arq Bras Oftalmol 2010;73:66-9.

30. Woodfield AS, Gower EW, Cassard SD, et al. Intraoperative phacoemulsification complication rates of second- and third-year ophthalmology residents: A 5-year comparison. Ophthalmology 2011;118:954-8.

31. Pokroy R, Du E, Alzaga A, et al. Impact of simulator 
training on resident cataract surgery. Graefes Arch Clin Exp Ophthalmol 2013;251:777-81.

32. Puri S, Kiely AE, Wang J, et al. Comparing resident cataract surgery outcomes under novice versus experienced attending supervision. Clin Ophthalmol 2015;9:1675-81.

33. Low SAW, Braga-Mele R, Yan DB, et al. Intraoperative complication rates in cataract surgery performed by ophthalmology resident trainees compared to staff surgeons in a Canadian academic center. J Cataract Refract Surg 2018;44:1344-9.

34. Borboli-Gerogiannis S, Jeng-Miller KW, Koulisis N, et al. A Comprehensive Surgical Curriculum Reduced Intraoperative Complication Rates of Resident-performed

Cite this article as: Aaronson A, Viljanen A, Kanclerz P, Grzybowski A, Tuuminen R. Cataract complications study: an analysis of adverse effects among 14,520 eyes in relation to surgical experience. Ann Transl Med 2020;8(22):1541. doi: 10.21037/atm-20-845
Cataract Surgeries. J Surg Educ 2019;76:150-7.

35. Yulan W, Yaohua S, Jinhua T, et al. Step-by-step phacoemulsification training program for ophthalmology residents. Indian J Ophthalmol 2013;61:659-62.

36. Patel SN, Ali SF, Clarke C, et al. Etiology and treatment outcomes of persistent postoperative inflammation in primary resident-performed cataract surgeries at a large tertiary care public hospital. J Cataract Refract Surg 2018;44:856-63.

37. Hosler MR, Scott IU, Kunselman AR, et al. Impact of resident participation in cataract surgery on operative time and cost. Ophthalmology 2012;119:95-8. 